\title{
Serum homocysteine concentrations of Chinese intellectuals and the influential factors concerned
}

\author{
Yue Hou*, Yan Hong, Wei-Qiang Chen, Dong-Lan Wang, Yi-Yong Cheng \\ *Institution of Hygiene and Environmental Medicine, Tianjin, China; Corresponding author: houy77@sohu.com
}

Received 23 July 2009; revised 6 August 2009; accepted 7 August 2009.

\begin{abstract}
Objective: To observe the concentration of serum homocysteine in intellectuals and the related influential factors. Methods: The concentrations serum homocysteine and saliva cortisol were measured in 138 intellectuals from three cities, Tianjin, Guangzhou and Chengdu in China. All the subjects had senior titles of technical post, aged 40-69 years. Results: The mean value of serum homocysteine concentration in intellectuals was $20.6 \pm 0.8 \mu \mathrm{mol} / \mathrm{L}$, higher than the reference value. With the increase of cortisol levels the homocysteine concentrations rise (P $<0.05$ ). The mean value of homocysteine concentration was highest in 40-49 years old group. Men had higher homocysteine level than women in this investigation. According to the mean value of homocysteine concentration among different cities, Tianjin was highest, Chengdu medium, Guangzhou lowest. Conclusion: The serum homocysteine concentration of intellectuals is higher than the reference value. The stress level, gender and resident cities might contribute to the differences in serum homocysteine concentration in Chinese intellectuals.
\end{abstract}

Keywords: Homocysteine; Psychological Stress; Intellectual

\section{INTRODUCTION}

Stress induces several physiological and behavioral alterations that increase cardiovascular morbidity and mortality [1-3]. It is well known that total plasma homocysteine (tHcy) is now established as a clinical risk factor for coronary artery disease, as well as other arterial and venous occlusive disease in adult populations [4]. Nonetheless, only a few studies have evaluated the relationship between stress and tHcy level. In order to examine whether any acute effect on total plasma Homo- cysteine (Hcy) concentrations in rats would occur four distinct acute stressors in rats, i.e., swimming, restrain, novelty and cold exposure were used. Plasma corticosterone and adrenocorticotropic hormone concentrations were also measured to demonstrate the ability of the chosen manipulations to activate the hypothalamic-pituitary-adrenal (HPA) axis. Three of the four stressors activated the HPA axis and only restrain increased tHcy concentrations [5]. Stoney et al.'s study was to test if acute psychological stress could induce elevations in plasma Hcy concentrations. Thirty-four healthy women participated in this study. The results indicated significant elevations in plasma Hcy during acute psychological stress, with a return to baseline concentrations during recovery [6]. The complexity of the physiological responses to stress, the peculiarities of stress responses and the intricate regulatory systems involved in Hcy metabolism must be taken into account in order to clarify the increasing effect of restrain (mainly a psychological stressor) on total plasma Hcy in rats and to evaluate its meaning in human pathology.

Stress is one of the biggest problems faced by intellectuals today. The increasingly demanding nature of their jobs has also increased pressure levels dramatically. Research shows that intellectuals are now facing greater day-to-day problems with occupational stress than most other employees. Psychological stressors and depressive and anxiety disorders also are associated with psychosomatic disease such as heart disease, hypertension and diabetes, which have become the main factors impairing the intellectuals' health [7-10]. The intellectuals were selected from different resident cities in China as subjects and their serum Hcy levels and some influential factors were observed.

\section{MATERIALS AND METHODS}

\subsection{Subjects}

One hundred and thirty-eight volunteers between the ages of 40 and 69 years (mean age $=54.2$ years) participated in the study after providing written informed consent. The 138 intellectuals come from three cities, Tianjin, 
Table 1. The distribution of subjects by area, age and sex.

\begin{tabular}{|c|c|c|c|c|c|c|c|}
\hline \multirow{2}{*}{ City } & \multicolumn{2}{|c|}{$40-49(y)$} & \multicolumn{2}{|c|}{$50-59(y)$} & \multicolumn{2}{|c|}{$60-69(y)$} & \multirow{2}{*}{ Total } \\
\hline & Male & Female & Male & Female & Male & Female & \\
\hline Tianjin & 8 & 8 & 8 & 8 & 8 & 8 & 48 \\
\hline Guangzhou & 5 & 5 & 5 & 5 & 5 & 5 & 30 \\
\hline Chengdu & 10 & 10 & 10 & 10 & 10 & 10 & 60 \\
\hline Total & \multicolumn{2}{|c|}{46} & \multicolumn{2}{|c|}{46} & \multicolumn{2}{|c|}{46} & 138 \\
\hline
\end{tabular}

Guangzhou and Chengdu, and all the subjects had senior titles of technical post in university or science research institute or design institute. The distribution of participants is presented in Table 1.

\subsection{Blood and Salivary Collection}

The fasting blood samples were collected into chilled tubes, and immediately immersed in ice. The serums were separated by centrifugation within 30-min and stored at $-20^{\circ} \mathrm{C}$ until analyses. The volunteers collected the saliva samples in the morning. Firstly they gargled three times, after 15 minutes they chaw on citric acid slips for a few seconds to stimulate salivation (not use gum or any other food-type product) and collected the salivary with straw. The samples stored at $-20^{\circ} \mathrm{C}$ within three hours and centrifuged before analysis $[11,12]$.

\subsection{Laboratory Analysis}

Total Hcy was measured in serum by the Total-Homocysteine Enzymatic Assay method [13]. The principle of the assay is as follows. In reaction I, rHCYase specifically converts Hcy to $\alpha$-ketobutyrate, ammonia, and $\mathrm{H}_{2} \mathrm{~S}$. In reaction II, the $\mathrm{H}_{2} \mathrm{~S}$ combines with DBPDA to form 3,7-bis (dibutyl amino) phenothiazine-5-ium chlorides, which is highly fluorescent. For the reduction reaction, flat-bottomed 96-well cell culture cluster plates with low-evaporationlids were used (cat. no. 0720089; Corning). Twenty microliters of serum samples and $170 \mathrm{uL}$ of assay buffer [40mmol/L sodium phosphate buffer $(\mathrm{pH}$ 8.4 ), containing $2 \mathrm{~mL} / \mathrm{L}$ Triton $\mathrm{X}-100$ and $0.25 \mathrm{mmol} / \mathrm{L}$ DTT] were added to the wells. Two wells were used for each sample. Reduction reaction was carried out at 37 ${ }^{\circ} \mathrm{C}$ for $30 \mathrm{~min}$. It is necessary to break the disulfide linkages in plasma proteins and to reduce the low molecular weight disulfides Hcy and homocysteine-cysteine mixed disulfide in this reaction. For each sample, we added $30 \mathrm{uL}$ of rHCYase $(0.05 \mathrm{~g} / \mathrm{L})$, the equivalent to 0.1 $\mathrm{U}$, in $40 \mathrm{mmol} / \mathrm{L}$ potassium phosphate buffer containing $20 \mu \mathrm{mol} / \mathrm{L}$ pyridoxal phosphate. One unit of enzyme is defined as the amount that catalyzes $1 \mu \mathrm{mol}$ of $\mathrm{H}_{2} \mathrm{~S}$ per minute from Hcy. We added $30 \mathrm{uL}$ of enzyme buffer to the other well to serve as background. The enzymatic reaction was carried out at room temperature for $5 \mathrm{~min}$. The lid was put on the dish to prevent possible loss of $\mathrm{H}_{2} \mathrm{~S}$. The enzymatic reaction was stopped by the addition of $30 \mathrm{uL}$ of chromophore reagent $(20 \mathrm{mmol} / \mathrm{L}$ DBPDA in $3 \mathrm{~mol} / \mathrm{L} \mathrm{H}_{2} \mathrm{SO}_{4}$ ). The chromogenic reaction was carried out at room temperature for $10 \mathrm{~min}$. The resulting fluorescence was measured at an excitation wavelength of $665 \mathrm{~nm}$ and an emission wavelength of $690 \mathrm{~nm}$ in Hcy special fluorescence spectral-photometer (JD Biotech Co., Ltd.).

Cortisol level was measured with a RIA kit, a product of Isotope Institute, Chinese Atomic Energy Science Academy [14].

\subsection{Statistical Analysis}

Continuous variables were summarized as the mean \pm SE. One-way ANOVA were used to compare group means. Statistical significance was defined as $\mathrm{P}<0.05$. Subjects with missing data were dropped from the analysis.

\section{RESULTS}

129 saliva samples were collected. The Hcy concentrations and the cortisol levels of all subjects were compared (see Figure 1). A significant relation between Hcy concentrations and the cortisol levels was observed $(\mathrm{r}=0.21, \mathrm{P}<0.05)$. With the increase of cortisol levels the Hcy concentrations rise.

The average level of salivary cortisol was $10.3 \mu \mathrm{g} / \mathrm{L}$. The subjects was divided into two groups, low cortisol group (LCor, $<10.3 \mu \mathrm{g} / \mathrm{L}$ ) and high cortisol group (HCor, $\geq 10.3$ $\mu \mathrm{g} / \mathrm{L})$. As expected the HCor had signify cantly higher serum concentrations of Hcy than the LCor (see Table 2).

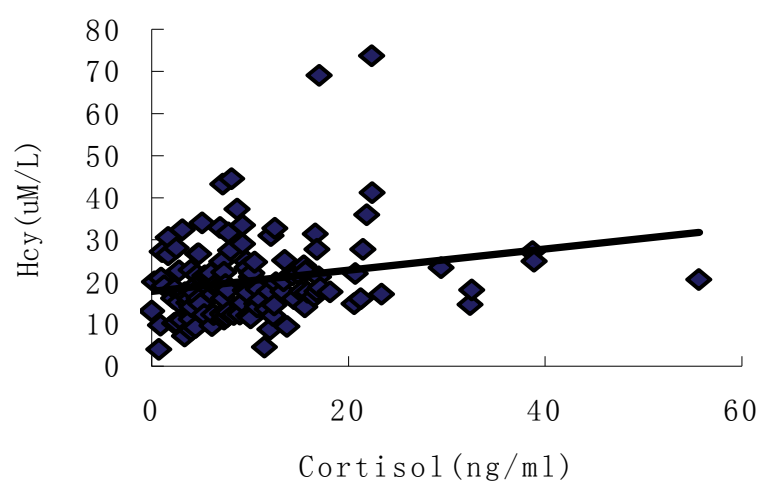

Figure 1. The correlation plots of serum Hcy and cortisol concentrations. 
Table 2. Saliva cortisol and serum homocysteine concentrations in LCor and HCor groups $\left(\bar{x} \pm s_{\bar{x}}\right)$.

\begin{tabular}{cccc}
\hline Group & $n$ & Cortisol $(\mu \mathrm{g} / \mathrm{L})$ & Hcy $(\mu \mathrm{mol} / \mathrm{L})$ \\
\hline LCor & 77 & $5.5 \pm 0.3$ & $18.4 \pm 0.8$ \\
HCor & 52 & $18.1 \pm 1.3$ & $22.0 \pm 1.7$ \\
Total & 129 & $10.3 \pm 0.7$ & $20.3 \pm 0.9$ \\
\hline$P<0.05$ & & &
\end{tabular}

$P<0.05$

Table 3. Comparison of serum homocysteine concentration by $\operatorname{age}\left(\bar{x} \pm s_{\bar{x}}\right)$.

\begin{tabular}{ccc}
\hline Age $(\mathrm{y})$ & $n$ & Hcy $(\mu \mathrm{mol} / \mathrm{L})$ \\
\hline $40-49$ & 46 & $23.2 \pm 1.6^{\mathrm{a}}$ \\
$50-59$ & 46 & $19.0 \pm 1.4^{\mathrm{b}}$ \\
$60-69$ & 46 & $19.5 \pm 1.2$ \\
Total & 138 & $20.6 \pm 0.8$ \\
\hline
\end{tabular}

Values with different superscripts are significantly different $(P<0.05)$

Table 4. Differences of serum homocysteine concentrations between male and female $\left(\bar{x} \pm s_{\bar{x}}\right)$.

\begin{tabular}{ccc}
\hline Sex & $n$ & Hcy $(\mu \mathrm{mol} / \mathrm{L})$ \\
\hline Male & 69 & $24.0 \pm 1.5$ \\
Female & 69 & $16.9 \pm 0.6$ \\
\hline$P<0.05$ & &
\end{tabular}

Table 5. Serum homocysteine concentrations of subjects in three $\operatorname{cities}\left(\bar{x} \pm s_{\bar{x}}\right)$.

\begin{tabular}{ccc}
\hline City & $n$ & Hcy $(\mu \mathrm{mol} / \mathrm{L})$ \\
\hline Tianjin & 48 & $22.4 \pm 1.5^{\mathrm{a}}$ \\
Guangzhou & 30 & $17.1 \pm 2.3^{\mathrm{b}}$ \\
Chengdu & 60 & $20.5 \pm 1.0$ \\
\hline
\end{tabular}

Values with different superscripts are significantly different $(P<0.05)$

The mean value of serum Hcy concentration in intellectuals was $20.6 \pm 0.8 \mu \mathrm{mol} / \mathrm{L}$. The mean value of Hcy concentration was highest in 40-49 years old and lowest in 50-59 years old. There was significant difference between 40-49 years group and 50-59 years group (see Table 3).

Among the subjects the average Hcy level of men was significant higher than women (see Table 4).

The average Hcy levels among the three cities were compared. The average Hcy level of the volunteers in Tianjin was highest, medium in Chengdu, lowest in Guangzhou. But only significant difference was observed between Tianjin and Guangzhou (see Table 5).

\section{DISCUSSION}

Hcy is a sulfur-containing amino acid generated through the demethylation of methionine. The resulting Hcy is either remethylated to methionine through methionine synthase (MS), a process that utilizes folate and vitamin B12 as cofactors, or catabolized by transsulfuration into cystathionine through cystathionine- $\beta$-synthetase (CBS) if excess Hcy is present, using vitamin B6 as cofactor [15]. It is also controlled by individual genetic differences in how vitamins are utilized as cofactors in the reactions controlling Hcy metabolism. In excess quantities, Hcy is thought to be thrombophilic and to damage the vascular endothelium. Total plasma homocysteine (tHcy) is now established as a independent risk factor for coronary artery disease, as well as other arterial and venous occlusive disease in adult populations [4,16-18].

The third National Health Examination Survey showed the first data on Hcy concentration in a nationally representative sample of Americans. The Survey measured serum total Hcy concentrations for a nationally representative samples of 3766 males and 4819 females aged $\geq 12 \mathrm{y}$. The normal total plasma Hcy concentrations of Americans was in the range of $5 \mu \mathrm{mol} / \mathrm{L}$ to $15 \mu \mathrm{mol} / \mathrm{L}$ and affected by age, sex and race [19]. Yan et al. reported that Chinese average plasma Hcy level reference was $(9.67 \pm 3.0) \mu \mathrm{mol} / \mathrm{L}, 95 \%$ confidence interval was $3.79 \mu \mathrm{mol} / \mathrm{L}$ to $15.55 \mu \mathrm{mol} / \mathrm{L}$. Zhang et al. investigated 1226 middle- and old-age people and the average plasma Hcy level was $9.1 \mu \mathrm{mol} / \mathrm{L}$ [20]. The present study reflected that the average serum Hcy level of the intellectuals aged 40-69 in Tianjin, Guangzhou and Chengdu was higher than the level other study showed.

It is now generally accepted that psychological stress is a multi-dimensional and multi-level phenomenon that is influenced by personal, situational or structural factors. Studies of occupational stress indicate that workload and communications are significant causes. Anticipation, worry, helplessness and executive roles have all emerged from laboratory studies as psychological factors inducing stress. Several studies concur in finding that poor working conditions, especially relationships with colleagues, overload, and poor school ethos are the major causes of intellectual stress. There is considerable evidence, mainly from self-reports, that intellectuals feel ill as a consequence of excessive stress. However, available absence and retirals statistics are not sufficiently specific to support this connection [8]. Generally cortisol level was recognized to be an index judging the degree of stress $[11,12]$. Our study showed that the serum Hcy concentration of high saliva cortisol concentration group was significant higher than low saliva cortisol concentration group. The result indicated that psychological stress could be one of the reasons causing the increase of serum Hcy level and the stress degree may connect with the level of serum Hcy. Stoney et al.'s study was to test the hypothesis that acute psychological stress induces elevations in plasma Hcy concentrations. Thirty-four healthy women participated in the study. The psychological stressors included standard mental arithmetic and speech stressors and heat rate and blood samples were also monitored. Results indicated significant elevations in plasma Hcy during acute psychological stress, with a 
return to baseline concentrations during recovery. The pattern of findings for blood pressure and heart rate was similar, suggesting that the rise in Hcy concentrations may have been sympathetically mediated [6]. But the related mechanism remains unclear.

It is known that many physiological variables influencing Hcy concentrations. Circulating tHcy increases with age in both genders-an effect that is partly due to decreasing renal function, partly due to increasing prevalence of subclinical and clinically demonstrable vitamin deficiency, or to other independent metabolic factors. In particular, aging may be associated with decrease CBS activity [21]. However our study showed that there is no trend of increase of Hcy concentrations with the increase of age. On the contrary in the three age group 40-49 years old group had highest level of serum Hcy. That the intellectuals in 40-49 years group carried more work, burden and stress may be the reason of their high Hcy concentration.

This investigation demonstrated that men had higher Hcy level than women and there are much epidemiological evidence identifying the similar result [22-27] .In a multicentre case-control study in Europe vascular disease of the coronary, cerebral, of peripheral vessels and 800 control subjects (570 men, 230 women) were enrolled. The tHcy comparison between the sexes was carried out among control subjects only. The results showed that fasting tHcy levels were lower in women than in men [21]. The gender difference in fasting tHcy may be caused by hormonal differences between men and women. The hypothesized tHcy-lowering effect of oestrogens is derived from the observation that tHcy concentrations are lower in pregnant than in non-pregnant women [28,29]. Strong evidence for the effects of hormones on plasma tHcy levels is derived from a study in which male to female transsexuals showed a decreased geometric mean tHcy, and female to male transsexuals an increase [30]. Dierkes et al.'s study comprised 336 men and women, aged 40 to 65 years, obtained from an ongoing recruitment procedure. Plasma tHcy, folate, vitamin B12, vitamin B6, fat-free mass, creatinine, testosterone and estradiol, protein, and hematocrit were detected. From the gender-related variables, tHcy correlated significantly with fat-free mass and testosterone and inversely with estradiol. The difference between genders with regard to tHcy was mainly explained by differences in fat-free mass, but also by estrodiol concentration [23].

This study demonstrated that the average serum Hcy concentration of intellectuals in Tianjin was significant higher than that in Guangzhou. Tianjin and Guangzhou are located in north and south of china respectively and there are many differences in diet habit, prandial structure and economic condition between these two cities. Hao et al.'s study investigated 2545 subjects' plasma folate concentrations, sampled from the representative rural and urban areas in the south and north of China aged 35 to 64 years. Plasma concentrations of folate in southern population were significant higher (16.9 $\mathrm{nmol} / \mathrm{L})$ than those in the north $(8.3 \mathrm{nmol} / \mathrm{L})$, and the prevalence of folate deficiency in the south $(5.8 \%)$ was significantly lower than that in the north (37.1\%) [31]. Folat level is one of the main nutrition factors that affects the level of Hcy in body, so the Hcy concentration difference between Tianjin and Guangzhou may due to the difference of folate condition in this two cities.

In conclusion, the serum homocysteine concentration of intellectuals is higher than that of normal people. The stress level, gender and resident cities might contribute to the differences in serum homocysteine concentration in Chinese intellectuals. The epidemiological study showed that Hcy is not only pro-atherogenic and pro-thrombotic, it is biologically plausible that high Hcy levels may cause brain injury and neuropsychiatric disorders. Cross-section and some longitudinal studies support increased prevalence of stroke and vascular dementia in hyper-homocysteinemic individuals. The evidence of increased neurodegeneration caused by hyper-homocysteine is accumulating [17,32-34]. Thus to study and control the serum Hcy level of intellectuals are very important to handle and improve the health condition of intellectuals. To verify the exact relation between psychological stress and the difference of Hcy level, much more study and intervention experiment should be conducted in the future.

\section{REFERENCES}

[1] Folkow, B. (2001) Mental stress and its importance for cardiovascular disorders; physiological aspects, "frommice-to-man". Scand Cardiovascular Journal, 35(3), 163-72.

[2] Zwerenz, R., Knickenberg, R.J., Schattenburg, L., and Beutel, M.E. (2004) Work-related stress and resources of psychosomatic patients compared to the general population. Rehabilitation (Stuttg), 43(1), 10-6.

[3] Von Kanel, R., Mills, P.J., Fainman, C., and Dimsdale, J.E. (2001) Effects of psychological stress and psychiatric disorders on blood coagulation and fibrinolysis: A biobehavioral pathway to coronary artery disease. Psychosomatic Medicine, 63(4), 531-44.

[4] Loralie, J. L. and David, E. C. C. (1999) Homocysteine. critical reviews in clinical laboratory sciences, 36(4), 365-406.

[5] Oliveira, A.C., Suchecki, D., Cohen, S., and Almeida, V. D. (2004) Acute stressor-selective effect on total plasma homocysteine concentration in rats. Pharmacology, Biochemistry and Behavior, 77(2), 269-273.

[6] Stoney, C.M. (1999) Plasma homocysteine levels increase in women during psychological stress. Life Sciences, 64(25), 2359-2365.

[7] Cooper, C.L. (1993) The role of stress in the health and disease process. British Journal of Hospital Medicine, 
50(9), 562.

[8] Valerie, W. (2002) Feeling the Strain an overview of the literature on teachers' stress. SCRE Research Report 109, $1-33$.

[9] Cooper, C.L. and Kelly, M. (1993) Occupational stress in head teachers: A national UK study. British Journal of Educational Psychology, 63(Pt 1), 130-143.

[10] Edwards, J.R., Cooper, C.L., Pearl, S.G., de Paredes, E.S., O'Leary, T., and Wilhelm, M.C. (1990) The relationship between psychosocial factors and breast cancer: some unexpected results. Behavior Medicine, 16(1), 5-14.

[11] Tunn, S., Mollmann, H., Barth, J., Derendorf, H., Krieg, M. (1992) Simultaneous measurement of cortisol in serum and saliva after different forms of cortisol administration. Clinical Chemistry, 38(8 Pt 1), 1491-1494.

[12] Bonnin, R., Villabona, C., Rivera, A., Guillen, E., Sagarra, E., Soler, J., and Navarro, M.A. (1993) Is salivary cortisol a better index than free cortisol in serum or urine for diagnosis of Cushing syndrome? Clinical Chemistry, 39(6), 1353-4.

[13] Tan,Y., Tang, L., Sun, X., Zhang, N., Han, Q., Xu, M., An, Z., Andrew, W., Perry, and Robert, M. H. (2000) Total-homocysteine enzymatic assay. Clinical Chemistry, 46(10), 1686-1688

[14] Morineau, G., Boudi, A., Barka, A., Gourmelen, M., Degeilh, F., Hardy, N., al-Halnak, A., Soliman, H., Gosling, J.P., Julien, R., Brerault, J.L., Boudou, P., Aubert, P., Villette, J.M., Pruna, A., Galons, H., and Fiet, J. (1997) Radioimmunoassay of cortisone in serum, urine, and saliva to assess the status of the cortisol-cortisone shuttle. Clinical Chemistry, 43(10), 1397-407.

[15] Finkelstein, J.D. and Martin, J.J. (1986) Methionine metabolism in mammals: adaptation to methionine excess. Journal of Biological Chemistry, 261(4), 1582-1587.

[16] Rees, M.M. and Rodgers, G.M. (1993) Homocysteine: association of a metabolic disorder with vascular disease and thrombosis. Thromb Research, 71(5), 337-359.

[17] Blundell, G., Rose, F.A., and Tudball, N. (1994) Homocysteine induced endothelial cell toxicity and its protection. Biochemical Society Transactions, 22(3), 341S.

[18] McCully, K.S. (1993) Chemical pathology of homocysteine. I. Atherogenesis. Annual of Clinical Laboratory Sciences, 23(6), 477-493.

[19] Jacques, P.F., Rosenberg, I.H., Roger, G., Selhub, J., Bowman, B.A., Gunter, E. W., Jacquelin, D., and Johnson, C. (1999) Serum total homocysteine concentrations in adolescent and adult Americans: results from The Third National Health and Nutrition Examination Survey. American Journal of Clinical Nutrition, 69(3), 482-489.

[20] Zhang, F.R., Hao, L., Wang, J.Y., Lu, Y.Y., Zhu, M.M., Jiang, X.Y., and Yu, N. (2003) The investigation of plasma homocysteine levels in middle- and old-aged people. Jiangsu Health Care, 5(4), 31-32.

[21] Sachdev,.P., (2004) Homocysteine and neuropsychiatric disorders. Revista Brasileira De Psiquiatria, 26(1), 4955.

[22] Verhoef, P., Meleady, R., Daly, L.E., Graham, I.M., Robinson, K., and Boers, G.H. (1999) Homocysteine, vitamin status and risk of vascular disease-effects of gender and menopausal status. European Heart Journal, 20(17), 1234-1244.

[23] Dierkes, J., Jeckel, A., Ambrosch, A., Westphal, S., Luley, C., and Boeing, H. (2001) Factors explaining the difference of total homocysteien between men and women in European Investigation into Cancer and Nutrition Potsdam study. Metabolism, 50(6), 640-645.

[24] Jacobsen, D.W., Gatautis, V.J., Green, R., Robinson, K., Savon, S.R., Secic, M., Ji, J., Otto, J.M., and Taylor, L.M. Jr. (1994) Rapid HPLC determination of total homocysteine and other thiols in serum and plasma: sex differences and correlation with cobalamin and folate concentrations in healthy subjects. Clinical Chemistry, 40(6), 873-881.

[25] Brattstrom, L., Lindgren, A., Israelsson, B., Andersson, A., and Hultberg, B. (1994) Homocysteine and cysteine: determinants of plasma levels in middle-aged and elderly subjects. Journal of International Medicine, 236(6), 633-641.

[26] Lussier-Cacan, S., Xhignesse, M., Piolot, A., Selhub, J., Davigonon, J., and Genest, J. Jr. (1996) Plasma total homocysteine in healthy subjects: sex specific relation with biological traits. American Journal of Clinical Nutrition, 64(4), 587-593.

[27] Andersson, A., Brattstrom, L., Israelsson, B., Isaksson, A., Hamfelt, A., and Hultberg, B. (1992) Plasma homocysteine before and after methionine loading with regard to age, gender, and menopausal status. European Journal Clinical Investigation, 22(2), 79-87.

[28] Kang, S.S., Wong, P.W.K., Zhou, J., and Cook, H.Y. (1986) Total homocysteine in plasma and amniotic fluid of pregnant women. Metabolism, 35(10), 889-891.

[29] Andersson, A., Hultberg, B., Brattstrom, L., and Isaksson, A., (1992) Decreased serum homocysteine in pregnancy. European Journal of Clinical Chemistry and Clinical Biochemistry, 30(6), 377-379.

[30] Giltay, E.J., Hoogeveen, E.K., Elbers, J.M.H., Gooren, L.J.G., Asscheman, H., and Stehouwer, C.D.A. (1998) Effects of sex steroids on plasma total homocysteine levels: a study in transsexual males and females. Journal of Clinical Endocrinology and Metabolism, 83(2), 550-553.

[31] Hao, L., Tian, Y., Zhang, F., Zhong, X.Y., Zhang, B.L., Tan, M., Tang, Y., and Li, Z. (2002) Variation of plasma folate levels in adults between some areas and different seasons in China. Chinese Journal of Prevention Medicine, 36(5), 308-310.

[32] Seshadri, S., Beiser, A., Selhub, J., Jacques, P.F., Rosenberg, I.H., D'Agostino, R.B., Wilson, P.W., and Wolf, P.A. (2002) Plasma homocysteine as a risk factor for dementia and Alzheimer's disease. The New England Journal of Medicine, 346(7), 476-483.

[33] Mattson, M.P., Kruman, I.I., and Duan, W. (2002) Folic acid and homocysteine in age-related disease. Ageing Research Reviews, 1(1), 95-111.

[34] Kuhn, W., Roebroek R., Blom, H., van Oppenraaij, D., Przuntek, H., Kretschmer, A., Buttner, T., Woitalla, D., and Muller, T. (1998). Elevated plasma levels of homocysteine in Parkinson's disease. European Neurology, 40(1), 225-227. 